\title{
Emergency Medications Order for Adults: Standardized Concentration System in Saudi Arabia
}

\author{
Yousef Ahmed Alomi* $(\mathbb{D}$, The \\ Former General Manager of General \\ Administration of Pharmaceutical Care, The \\ Former Head, National Clinical pharmacy and \\ pharmacy practice, The Former Head, Phar- \\ macy R\&D Administration, Ministry of Health, \\ Riyadh, SAUDI ARABIA. \\ Manal Mansour Al Nemari, \\ Supervisor, Pharmacy Informatics and \\ Automation, King Fahad Medical City, Riyadh, \\ SAUDI ARABIA.
}

Fatimah Al-Doughan, College of Pharmacy, Pharmacy Practice Department, King Faisal University, Alhassa, SAUDI ARABIA. Yasir Ahmed Ibrahim, Head of Pharmacy Practice Department, Pharmacy Practice Department, College of Clinical Pharmacy, King Faisal University, Alahssa, SAUDI ARABIA

Hussam Saad Almalki, Supervisor of IV admixture services, Aleman Hospital, Ministry of Health, Riyadh, SAUDI ARABIA.

Nouf Alaza, Director of Medication Safety Officer, Pharmacy Services, Alyam $\neg$ mama Hospital, Ministry of Health, Riyadh, SAUDI ARABIA.

Malika Alshamari, Head, Pharmacy services, Alyamma Hospital, Ministry of Health, Riyadh, Saudi Arabia.

\section{Correspondence:}

Dr. Yousef Ahmed Alomi, The Former General Manager of General Administration of Pharmaceutical Care, The Former Head, National Clinical pharmacy and pharmacy practice, The Former Head, Pharmacy R\&D Administration, Ministry of Health, Riyadh, SAUDI ARABIA.

Phone no: +966 504417712

E-mail:yalomi@gmail.com

Received: 11-04-2019;

Accepted: 19-08-2019

Copyright: () the author(s), publisher and licensee International Journal of Pharmacology and Clinical Sciences. This is an open-access article distributed under the terms of the Creative Commons Attribution Non-Commercial License, which permits unrestricted non-commercial use, distribution, and reproduction in any medium, provided the original work is properly cited.

This is an open access article distributed under the terms of the Creative Commons Attribution-NonCommercial-ShareAlike 4.0 License

Access this article online

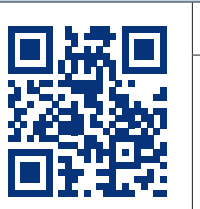

www.ijpcs.net

DOI:

10.5530/ijpcs.2019.8.44

\begin{abstract}
The general administration of pharmaceutical care released several publications related to the administration of intravenous medications, which mention about the concentration of intravenous medications for adults, pediatrics and neonatal patients. The publications also include several emergency medications with their concentrations. This new initiative was started in order to guide physicians to select the primary emergency medications in intravenous drip administration. The medications were selected based on common evidence-based standardized concentration for adults. This project required to control high-alert medications and prevent drug-related errors. The list of medications may be covered as computerized physician order entry and this project may be implemented as pharmacy project management.

Keywords: Adults, Emergency, Medications, Standardized Concentration, Saudi Arabia.
\end{abstract}

\section{INTRODUCTION}

The national medication safety program at the Ministry of Health, Kingdom of Saudi Arabia, was founded in 2013. ${ }^{[1]}$ This program has a strategic plan for several years and follows the national and international accreditation organization, for instance, Saudi Central Board for Accreditation of Healthcare Institutions (CBAHI) and Joint Commission. ${ }^{[2,3]}$ In addition, the program is collaborated with the Institute for Safe Medication Practices (ISMP)-the organization for medication safety in the United States of America (USA). The ISMP has several assessments related to the medications safety in the hospitals and in ambulatory care setting. ${ }^{[4,5]}$ The American Society of Health-System Pharmacist (ASHP) launched standardized concentration before several years. ${ }^{[6]}$ Recently, the first national survey of medication safety through ISMP assessment was conducted during the Hajj period in Saudi Arabia. [7-12] The principal defect point of the critical elements of the ISMP assessment was the standardized concentration of medications during administration through drug devices. ${ }^{[9,10]}$ The new initiative of adults emergency medications with standardized concentration and administration to improve medication safety culture and prevent medication error-related issues at three hospitals in Riyadh city, Saudi Arabia. To the best of our knowledge, there are no publications in Saudi Arabia, Gulf, or in Middle Eastern countries describing the standardized concentration of emergency medications for adults.

\section{Adults Emergency Medications Standardized Concentration in Saudi Arabia}

The standardized formulation of emergency medications include cardiopulmonary resuscitation requirements for adults. The formulation was derived from the current literature and guidelines for adults with an average body weight of $70 \mathrm{~kg}$. The medication consists of dopamine, dobutamine, epinephrine, norepinephrine and so on. The physician order form consisted of several parts: Patient's demographic data, medication names, the standardized concentration and maximum concentration of the medication, the type of crystallized fluid the type of administration through a central or peripheral vein, the dosing range as explored in the physician order entry form (Figure 1).

\section{SWOT Analysis}

The Strengths, Weaknesses, Opportunities and Threats (SWOT) analysis method was used in this project. The strengths of the physician order forms for adults includes all information regarding common medications used in emergency situations, dosing of medications, fixed standardized concentration of emergency medications, the method of administration and prevented mistakes in writing emergency medications orders for adults are available. The weaknesses include dosing drips used outside another's resources and it cannot apply to diseases such as renal or hepatic failure. The opportunities include a straightforward form to convert the physician order form into a computerized and physician order entry; it can perform statistical calculations on all emergency care medications. The threat points include the physician or the pharmacist not using the standardized concentration.

\section{Implementations Steps of Emergency Medications Standardized Concentration for Adults}

The pharmacy department organizes consultation with the committee of expert pharmacists especially from those experts on intravenous admixture and clinical pharmacists in critical care in the pharmacy department. The commit- 
tee should extensively review and then approve the standardized concentration form of adults' emergency medications form. The head of the committee will contact with the surgical and medical department for final revisions of the draft and its approval. The head of pharmacy services will submit the final draft of the formulation to the pharmacy and therapeutic committee for review and approval. The head of the committee will arrange with computer department to prepare electronic order forms. The pharmacy education coordinator arranges with all departments including nursing, surgical and medical department to educate and train the medical staff about using the formulation in addition to the pharmacy staff. The pharmacy quality management will set up the Key Performance Indicators (KPIs) to measure the impact of the project. All pharmacyrelated teams including emergency medications preparation and clinical pharmacist will collect the KPIs of the project retrospectively over 3-6 months. Another collection of the data prospectively after implementations. The head of the committee will contact the nursing and medical department to start with one medical department as the pilot trial. The pharmacist will review the pilot trial and correct the form according to the pharmacy consultation committee. The team will expand to all medical department and surgical department. Review and alter the shape accordingly through committee. The head of the committee will expand to all hospital department including adult's critical care, review and adjust the formulation accordingly. The pharmacy quality management coordinator measures the impact of the project by comparing the KPI before starting the project. The head of the committee will analyze the results and review with the consultation committee. The head of the pharmacy will submit the final report to the pharmacy and therapeutic committee for final comments. The consultation team reviews the final comments on the project, update it accordingly and continue the project with next year

\section{CONCLUSION}

The standardized concentration of emergency medications for adults is an essential demand to prevent attributable errors and improve patient outcomes in addition to the regulatory requirements of high-alert medications at the Ministry of Health hospitals in the Kingdom of Saudi Arabia.

\section{ACKNOWLEDGEMENT}

None.

\section{CONFLICT OF INTEREST}

The authors declare that there are no conflicts of interest.

\section{ABBREVIATIONS}

KSA: Kingdom of Saudi Arabia; MOH: Ministry of Health; USA: United States of America; CBAHI: Saudi Central Board for Accreditation of Healthcare Institutions; ISMP: Institute of Safe Medication Practice; SWOT: Strengths, Weaknesses, Opportunities and Threats; KPIs: Key Performance Indicators.

\section{ORCID ID}

Yousef Ahmed Alomi org/0000-0003-1381-628X

https://orcid.

\section{REFERENCES}

1. Alomi YA. National Medication Safety Program at Ministry of Health in Saudi Arabia. J Pharmacovigi. $2015 ; 3(5): 1-2$
2. Medication Management (MM). In: National Hospital Standards. $2^{\text {nd }}$ Editio. Saudi Central Board for Accreditation of Healthcare Institutions. 2015;194211. Available from: http://www.cbahi.gov.sa

3. The Joint Commission. 2016 Comprehensive Accreditation Manuals. Joint Commission Resources. 2016.

4. Institute for Safe Medication Practices. 2011 ISMP Medication Safety Self Assessment for Hospitals, Key Definitions. 2011;1-4. Available from: http:// ismp.org/selfassessments/Hospital/2011/definitions.pdf

5. Alex JA, Ronna BH, Coleen KE, et al. 2017 ISMP Medication Safety Self Assessment $₫$ for Community/Ambulatory Pharmacy. 2017.

6. American Society of Health-System Pharmacists. Standardized Concentrations: Adult Continuous IV Infusions Version 1.01. 2016.

7. Alomi YA, Khayat NAY, Baljoon MJ, Bamagaus YA, Jumah HMA. National Survey of Hospital Medication Safety Practice during Mass Gathering (Hajj-2016) in Makkah, Saudi Arabia: Patient Information. J Pharm Pract Community Med. 2017;3(4s):s29-35.

8. Alomi YA, Khayat NAY, Baljoon MJ, Bamagaus YA, Jumah HMA. National Survey of Hospital Medication Safety Practice during Mass Gathering (Haij2016) in Makkah, Saudi Arabia: Drug Information. J Pharm Pract Community Med. 2017;3(4s):s8-14.

9. Alomi YA, Khayat NAY, Baljoon MJ, Bamagaus YA, Jumah HMA. National Survey of Hospital Medication Safety Practice during Mass Gathering (Hajj2016) in Makkah, Saudi Arabia: Medication Preparation and Dispensing. J Pharm Pract Community Med. 2017;3(4s):s36-42.

10. Alomi YA, Khayat NAY, Baljoon MJ, Bamagaus YA, Jumah HMA. National Survey of Hospital Medication Safety Practice during Mass Gathering (Hajj-2016) in Makka, Saudi Arabia: Medication Administration. J Pharm Pract Community Med. 2017;3(4s):s22-8

11. Alomi YA, Khayat NAY, Baljoon MJ, Bamagaus YA, Jumah HMA. National Survey of Hospital Medication Safety Practice during Mass Gathering (Hajj-2016) in Makkah, Saudi Arabia: Environmental Culture and Staff Competency. J Pharm Pract Community Med. 2017;3(4s):s15-21.

12. Alomi YA, Khayat NAY, Baljoon MJ, Bamagaus YA, Jumah HMA. National Survey of Hospital Medication Safety Practice during Mass Gathering (Hajj2016) in Makkah, Saudi Arabia: Patient Education, Quality Process and Risk Management. J Pharm Pract Community Med. 2017;3(4s):s1-7. 


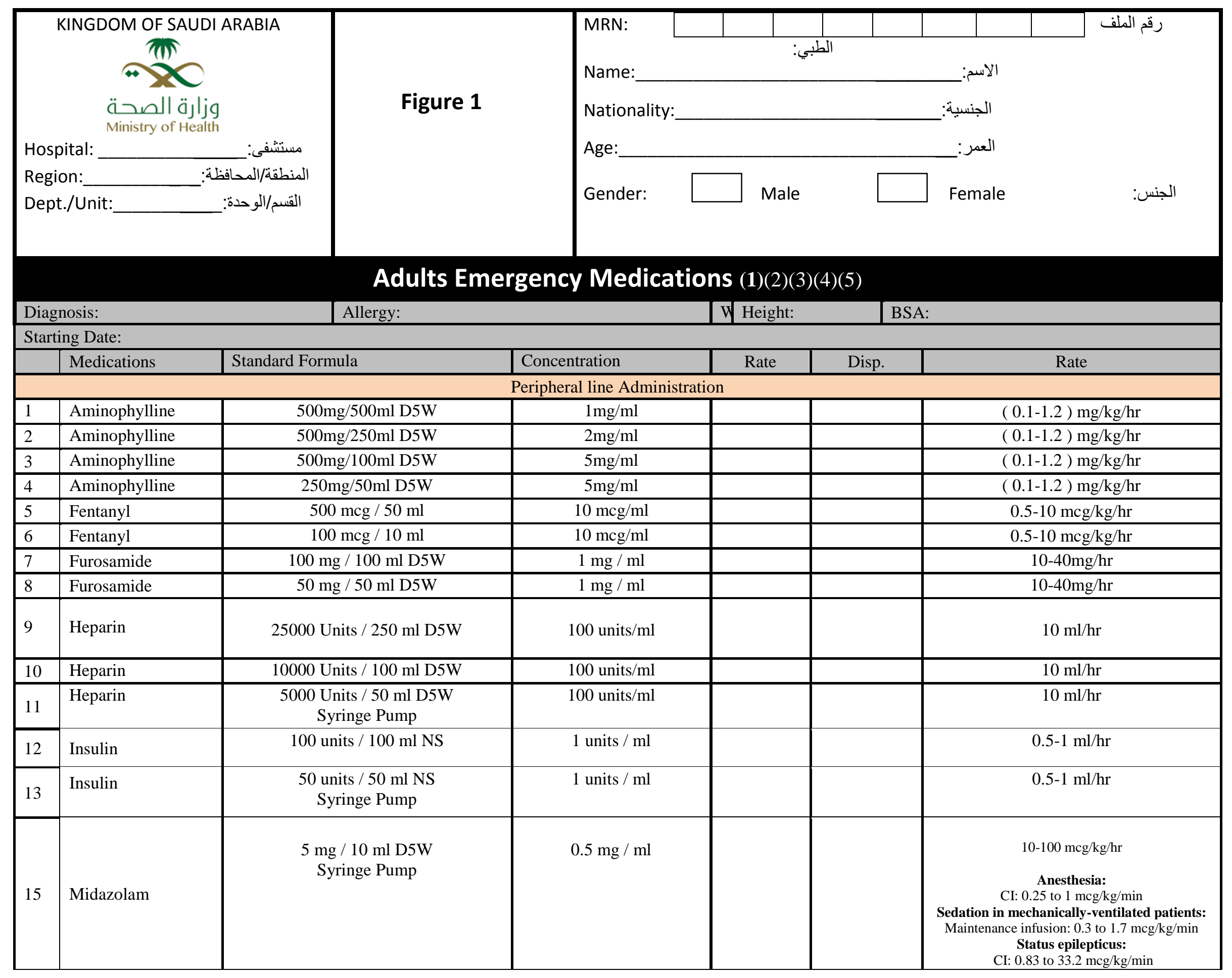




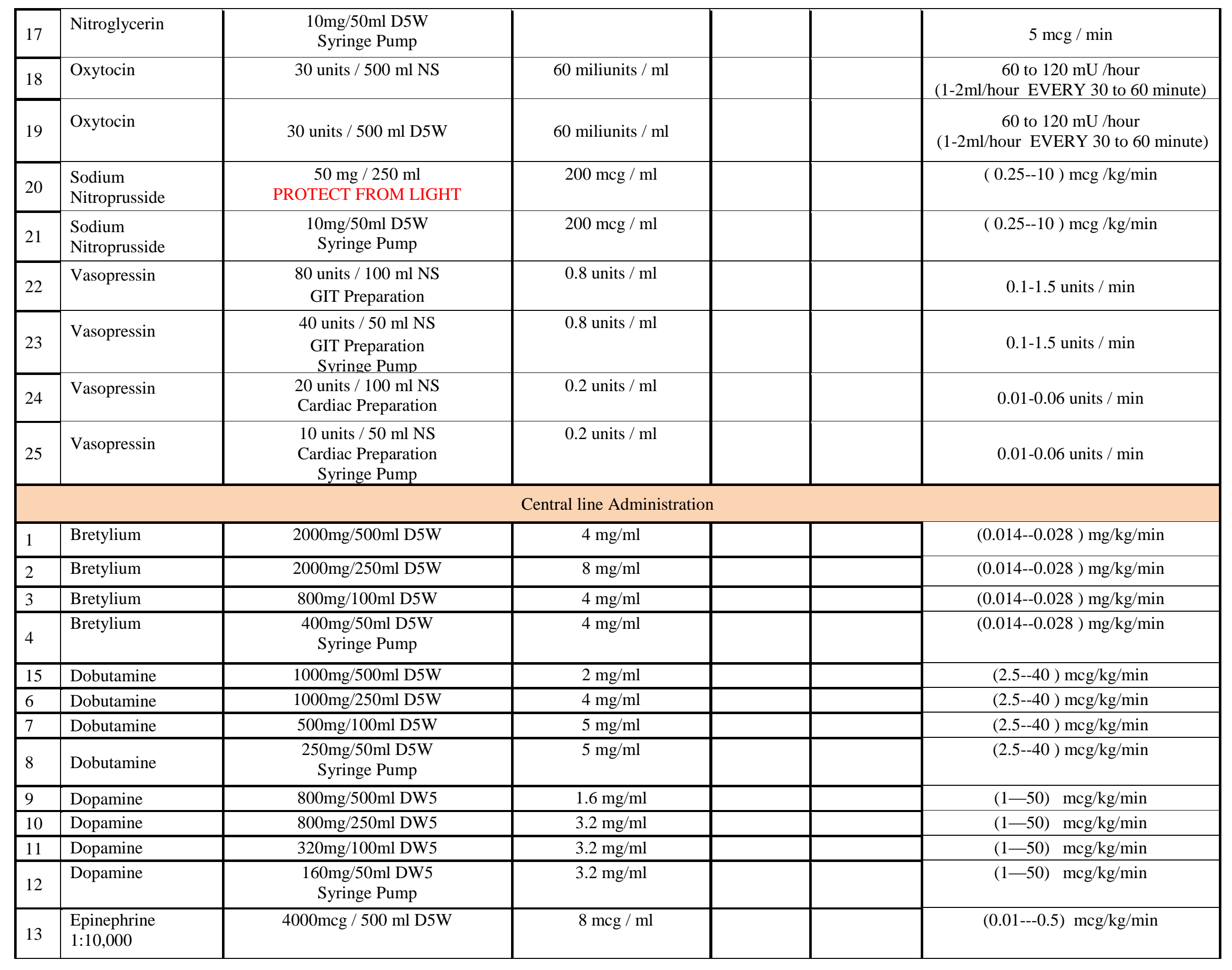




\begin{tabular}{|c|c|c|c|c|c|}
\hline 14 & $\begin{array}{l}\text { Epinephrine } \\
1: 10,000\end{array}$ & $4000 \mathrm{mcg} / 250 \mathrm{ml} \mathrm{D} 5 \mathrm{~W}$ & $16 \mathrm{mcg} / \mathrm{ml}$ & & $(0.01---0.5) \mathrm{mcg} / \mathrm{kg} / \mathrm{min}$ \\
\hline 15 & $\begin{array}{l}\text { Epinephrine } \\
1: 10,000\end{array}$ & $2000 \mathrm{mcg} / 100 \mathrm{ml}$ D5W & $20 \mathrm{mcg} / \mathrm{ml}$ & & $(0.01---0.5) \mathrm{mcg} / \mathrm{kg} / \mathrm{min}$ \\
\hline 16 & $\begin{array}{l}\text { Epinephrine } \\
1: 10,000\end{array}$ & $\begin{array}{l}\text { 1000mcg / } 50 \mathrm{ml} \mathrm{D5W} \\
\text { Syringe Pump }\end{array}$ & $20 \mathrm{mcg} / \mathrm{ml}$ & & $(0.01---0.5) \mathrm{mcg} / \mathrm{kg} / \mathrm{min}$ \\
\hline 16 & Isoproterenol & $1000 \mathrm{mcg} / 250 \mathrm{ml}$ D5W & $4 \mathrm{mcg} / \mathrm{ml}$ & & $(2--20) \mathrm{mcg} / \mathrm{min}$ \\
\hline 17 & Isoproterenol & $400 \mathrm{mcg} / 100 \mathrm{ml}$ D5W & $4 \mathrm{mcg} / \mathrm{ml}$ & & $(2--20) \mathrm{mcg} / \mathrm{min}$ \\
\hline 18 & Isoproterenol & $200 \mathrm{mcg} / 50 \mathrm{ml}$ D5W & $4 \mathrm{mcg} / \mathrm{ml}$ & & $(2--20) \mathrm{mcg} / \mathrm{min}$ \\
\hline 19 & Lidocaine & $2000 \mathrm{mg} / 500 \mathrm{ml} \mathrm{D} 5 \mathrm{~W}$ & $4000 \mathrm{mcg} / \mathrm{ml}$ & & $(1--4) \mathrm{mg} / \mathrm{min}$ \\
\hline 20 & Lidocaine & $2000 \mathrm{mg} / 250 \mathrm{ml} \mathrm{D} 5 \mathrm{~W}$ & $8000 \mathrm{mcg} / \mathrm{ml}$ & & $(1--4) \mathrm{mg} / \mathrm{min}$ \\
\hline 21 & Lidocaine & $800 \mathrm{mg} / 100 \mathrm{ml} \mathrm{D} 5 \mathrm{~W}$ & $8000 \mathrm{mcg} / \mathrm{ml}$ & & $(1--4) \mathrm{mg} / \mathrm{min}$ \\
\hline 22 & Lidocaine & $\begin{array}{l}400 \mathrm{mg} / 50 \mathrm{ml} \mathrm{D} 5 \mathrm{~W} \\
\text { Syringe Pump }\end{array}$ & $8000 \mathrm{mcg} / \mathrm{ml}$ & & $(1--4) \mathrm{mg} / \mathrm{min}$ \\
\hline 23 & Norepinephrine & $4000 \mathrm{mcg} / 500 \mathrm{ml} \mathrm{D5W}$ & $8 \mathrm{mcg} / \mathrm{ml}$ & & $\begin{array}{c}\text { Initial: }(0.1---0.3) \mathrm{mg} / \mathrm{kg} / \mathrm{min} \\
\text { Maintenance: } \\
(0.01---0.06) \mathrm{mcg} / \mathrm{kg} / \mathrm{min}\end{array}$ \\
\hline 24 & Norepinephrine & $4000 \mathrm{mcg} / 250 \mathrm{ml} \mathrm{D} 5 \mathrm{~W}$ & $16 \mathrm{mcg} / \mathrm{ml}$ & & $\begin{array}{c}\text { Initial: }(0.1---0.3) \mathrm{mg} / \mathrm{kg} / \mathrm{min} \\
\text { Maintenance: } \\
(0.01---0.06) \mathrm{mcg} / \mathrm{kg} / \mathrm{min}\end{array}$ \\
\hline 25 & Norepinephrine & $4000 \mathrm{mcg} / 100 \mathrm{ml} \mathrm{D} 5 \mathrm{~W}$ & $40 \mathrm{mcg} / \mathrm{ml}$ & & $\begin{array}{c}\text { Initial: }(0.1---0.3) \mathrm{mg} / \mathrm{kg} / \mathrm{min} \\
\text { Maintenance: } \\
(0.01---0.06) \mathrm{mcg} / \mathrm{kg} / \mathrm{min}\end{array}$ \\
\hline 26 & Norepinephrine & $\begin{array}{l}2000 \mathrm{mcg} / 50 \mathrm{ml} \mathrm{D} 5 \mathrm{~W} \\
\text { Syringe Pump }\end{array}$ & $40 \mathrm{mcg} / \mathrm{ml}$ & & $\begin{array}{c}\text { Initial: }(0.1---0.3) \mathrm{mg} / \mathrm{kg} / \mathrm{min} \\
\text { Maintenance: } \\
(0.01---0.06) \mathrm{mcg} / \mathrm{kg} / \mathrm{min}\end{array}$ \\
\hline 27 & Procainamide & $1000 \mathrm{mg} / 250 \mathrm{ml}$ D5W & $4000 \mathrm{mcg} / \mathrm{ml}$ & & $(1-6) \mathrm{mg} / \mathrm{min}$ \\
\hline 28 & Procainamide & $400 \mathrm{mg} / 100 \mathrm{ml}$ D5W & $4000 \mathrm{mcg} / \mathrm{ml}$ & & $(1-6) \mathrm{mg} / \mathrm{min}$ \\
\hline 29 & Procainamide & $\begin{array}{c}200 \mathrm{mg} / 50 \mathrm{ml} \mathrm{D} 5 \mathrm{~W} \\
\text { Syringe Pump }\end{array}$ & $4000 \mathrm{mcg} / \mathrm{ml}$ & & $(1-6) \mathrm{mg} / \mathrm{min}$ \\
\hline \multicolumn{6}{|c|}{$\begin{array}{l}\text { References } \\
\text { 1. } \quad \text { Micromedex Solution App. Colistimethate Sodium. IBM Corporation; } 2018 . \\
\text { 2. } \\
\text { 3. } \\
\text { Alomi YA, et al. Adults Parenteral Dilution Manual. 1st Editio. General Adminstration of Pharmaceutical Care - Ministery of Health; } 2015 . \\
\text { 4. } \\
\text { 5. }\end{array}$} \\
\hline \multicolumn{2}{|c|}{ Physician sig.: } & & & \multicolumn{2}{|l|}{ Pharmacist sig.: } \\
\hline \multicolumn{2}{|c|}{ Nurse sig.: } & & & Pharmacist sig.: & \\
\hline
\end{tabular}

